\title{
EFFECT OF LATHE CUTTING CONDITIONS ON THE HARDNESS OF CARBON AND ALLOY STEELS
}

\author{
By T. G. Digges
}

Previous work at the Bureau of Standards on machinability has been primarily concerned with the relation of the composition and heat treatment of both the tools and the steels cut to lathe-tool life. An investigation recently completed had a quite different object, namely, a quantitative study of the work hardening near the machined surface of steel forgings resulting from cutting with lathe tools.

Comparisons were made of the work hardening resulting from changes in size, form, and composition of tools; speed, feed, and depth of cut; and composition and heat treatment of the steels cut. Observations were also made of the influence of cutting conditions on aging, corrosion resistance, chip hardness, structure near the machined surface of some of the steels cut, and of the effect of annealing temperatures $\left(100^{\circ}\right.$ to $720^{\circ} \mathrm{C}$.) on the surface hardness of some of the steels work hardened in the lathe tests. All the lathe tests were made without cutting liquids and with sharp high-speed steel or cemented tantalum carbide tools. A detailed report of this work was contributed to the American Society of Mechanical Engineers and presented at the annual meeting of the society, New York, N. Y., December 5 to $9,1932$.

The amount and extent of work hardening of the forgings caused by the lathe tools was determined by making hardness surveys with a Vickers machine using a $10 \mathrm{~kg}$ load on the diamond pyramid having an included angle of $136^{\circ}$.

The hardness as close to the machined surface as it was possible to measure it was greater than the original hardness of the forging. The hardness decreased at increasing depths below the machined surface until it was the same as the original forging.

The amount of work hardening - that is, both the magnitude of the surface hardness and the depth of hardening-was not influenced by changes in the cutting speeds of the lathe tools.

With a given area of cut, the amount of work hardening was affected equally by changes in the feed or depth of cut. The work hardening depended not only upon the cutting conditions, such as the area of cut, but also upon the composition and heat treatment of the steels cut. Furthermore, two steels similar in chemical composition and heat treatment had different work-hardening properties.

Data on the work hardening of 10 annealed plain carbon steel forgings, with carbon contents varying from 0.12 to 1.10 per cent, with three different areas of cut are summarized in Figure 1. The increase in surface hardness is plotted against the carbon contents. The hardness of the annealed steels before machining is also represented graphically: For the cutting conditions under consideration, the steel of lowest carbon content, namely, 0.12 per cent, showed the greatest increase in hardness at the machined surface. The work 
hardness at the surface decreased rapidly as the carbon content increased to about 0.4 per cent and then less rapidly with further increase in the carbon content of the annealed steels.

The depth to which the annealed carbon steels were hardened with the different areas of cut appeared to decrease uniformly with increase in carbon contents.

With small areas of cut, approximately 0.003 square inch, the surface hardness of an annealed 0.12 per cent carbon steel and an annealed carbon steel screw stock forging increased by about the same amount, but with the heavy cuts the screw stock had the highest increase in surface hardness. The depth of work hardening for all similar areas of cut was greater with the plain carbon steel than with the screw stock.

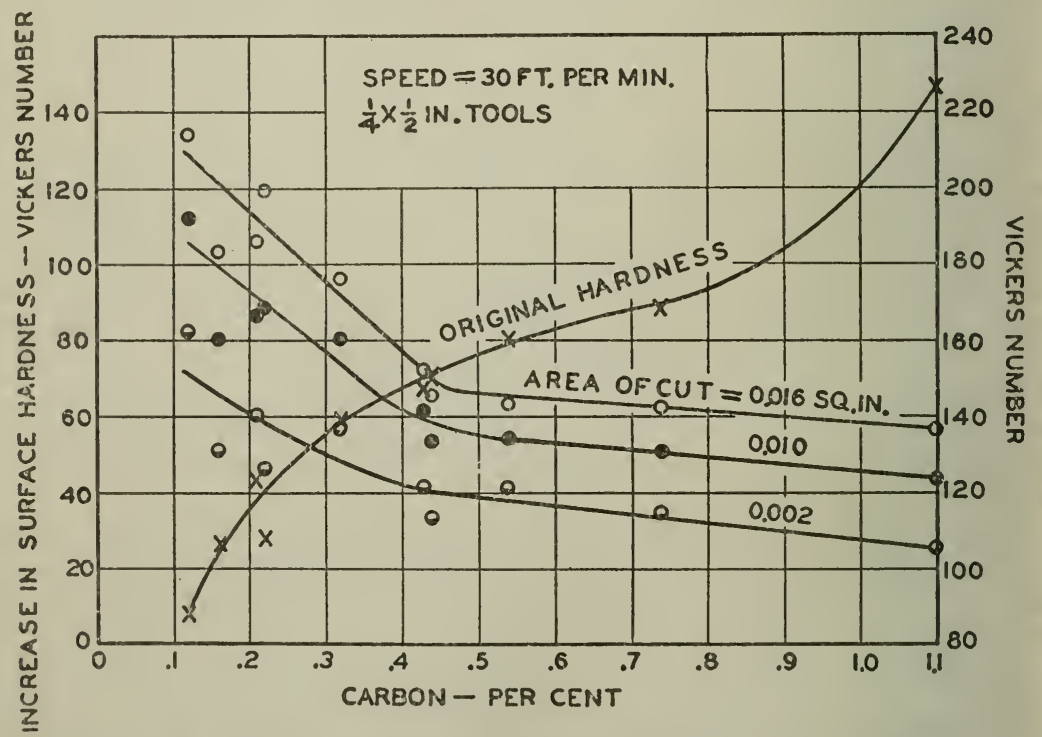

FIGURE 1.-Influence of the carbon contents of the steel cut upon the surface work hardening with different areas of cut

Stainless steel of the ordinary "18-8" (18 Cr, $8 \mathrm{Ni}$ ) composition (not free machining) had a very high capacity to work harden near the machined surface even with small areas of cut, but with increase in area of cut the change in work hardening values was not so marked. The "free-machining" "18-8" stainless steel with small areas of cut had no marked increase in surface hardness, but with increase in area of cut there was a continuous increase in the hardness.

Work-hardening the ordinary " $18-8$ " stainless steel in the lathe tests to the extent of increasing the surface hardness about 40 to 100 per cent had no marked influence on the resistance of the steel to hot nitric acid attack.

The hardness of the cold-worked plain carbon and $3 \frac{1}{2}$ per cent nickel steel was, in general, increased by annealing within the range of $100^{\circ}$ to $400^{\circ} \mathrm{C}$., but with further increase in annealing temperature the hardness decreased. The hardness from cold working with lathe tools was removed by heating to $720^{\circ} \mathrm{C}$.

Washington, October 8, 1932. 